\title{
Stress Testing Credit Risk: A Survey of Authorities' Approaches*
}

\author{
Antonella Foglia \\ Banking and Financial Supervision, Bank of Italy
}

\begin{abstract}
This paper reviews the quantitative methods developed at selected authorities for stress testing credit risk, focusing in particular on the methods used to link macroeconomic drivers of stress with bank-specific measures of credit risk (macro stress test). Authorities with a mandate for financial stability are particularly interested in quantifying the macro-to-micro linkages and have developed specific modeling expertise in this field. Stress testing credit risk is also an essential element of the Basel II framework, and some stress-testing requirements of Basel II are formulated by making explicit reference to the economic cycle. The paper highlights recent developments in macro stress testing and details a number of methodological challenges that may be useful for supervisors in their review process of banks' models as required by Basel II. It also contributes to the ongoing macroprudential research efforts to integrate macroeconomic oversight and prudential supervision, for early detection of key vulnerabilities and assessment of macro-financial linkages.
\end{abstract}

JEL Codes: E32, E37, G21.

\section{Introduction}

This paper reviews the quantitative methods developed at selected central banks and supervisory authorities to assess the

${ }^{*}$ The views expressed in this paper are those of the author and do not necessarily reflect those of Banca d'Italia. Work on this paper was initiated by the Basel Committee Research Task Force Group on Stress Testing. The author would like to thank the group members for their input, comments, and suggestions and especially A. Garcia Pascual, P. Kupiec, and I. van Lelyveld. Author contact: Banca d'Italia, Servizio Normativa e Politiche di vigilanza, Via Milano 53, Roma. Tel: +39647924553. E-mail: antonella.foglia@bancaditalia.it. 
vulnerabilities of financial systems to credit risk, focusing in particular on methods used to link macroeconomic drivers of stress with bank-specific measures of credit risk. It is based on a number of recent papers and internal documentation provided by supervisors and central banks. The models included in this survey are listed in table 1 in the appendix.

Financial sector stress tests provide information on a system's potential losses under exceptional but plausible shocks, helping policymakers assess the significance of the system's vulnerabilities. The value added by system stress tests derives from a consultative process that combines a forward-looking macroeconomic perspective, a focus on the financial system as a whole, and a uniform approach to the assessment of risk exposures across institutions. ${ }^{1}$ System stress tests can complement those of individual institutions and provide a cross-check for other types of analysis.

For many authorities the practice of stress testing was introduced as part of the Financial Sector Assessment Programs (FSAPs) conducted by the International Monetary Fund and the World Bank. The FSAP stress tests stimulated widespread research interest in developing new techniques, and many additional studies are under way. The survey includes methodologies that were used during the FSAPs and other studies developed afterward at the individual agencies.

The focus on credit risk and on the "macro-to-micro" models reflects a number of concerns: (i) stress testing credit risk is an essential element of the Basel II framework (Basel Committee on Banking Supervision 2005), and some stress-testing requirements of Basel II - such as the IRB-cyclicality stress tests (par. 435-37) and the forward-looking stress testing in the internal capital adequacy and assessment process (ICAAP) (par. 726) — are formulated by making explicit reference to the economic cycle (e.g., mild recession scenarios) and the macroeconomic background of a stress event; (ii) in this area, sound industry practices have not yet been established, and the translation of a stress event defined in terms of macroeconomic variables into movements in bank micro variables often represents a challenge for individual banks; and (iii) both in the FSAP context

\footnotetext{
${ }^{1}$ See International Monetary Fund and the World Bank (2003).
} 
and more generally for financial stability analysis, it is also one of the modeling areas most in need of further development. ${ }^{2}$

Because of their mandate for financial stability, central banks and supervisors are particularly interested in quantifying the macroto-micro linkages and have developed specific modeling expertise. Such expertise can be a useful starting point to develop a common analytical background because, in this field, supervisors and banks often face the same methodological challenges. Sections 2-6 review the current stress-testing practices across various supervision and financial stability authorities, comparing features and outlining the latest developments. Section 7 discusses a number of technical issues that may be relevant for supervisors in reviewing the Basel II stress-testing requirements. As methods to better incorporate macro/systemwide conditions as drivers of default risk and macro stress testing in general are among the main tools of supervisors with a "macroprudential" orientation, the discussion can also contribute to the ongoing analytical efforts to integrate macroeconomic oversight and prudential supervision, as recently advocated by the Financial Stability Forum. ${ }^{3}$ Section 8 concludes and sets out a research agenda.

\section{The Stress-Testing Process}

In all the approaches surveyed, macro stress testing can be seen as a multistage process, as shown in figure 1 .

The first step is to put together a coherent stress-test scenario, typically using a macroeconometric model. The scenario or the model may include endogenous policy responses. Given that such models do not generally include financial sector variables, the stresstesting framework usually includes "satellite" models (i) to map macroeconomic variables to some "key" financial variables, such as asset prices (typically, housing prices) and credit growth and (ii) to map macroeconomic and financial variables into financial sector measures of asset quality and potential credit losses. Total bank losses are calculated by aggregating credit and market losses, in some cases including additional allowances for the impact on net interest

\footnotetext{
${ }^{2}$ See the discussion in Swinburne (2007).

${ }^{3}$ See Financial Stability Forum (2008).
} 


\section{Figure 1. Credit Risk-A Typical Macro Stress-Testing Process}

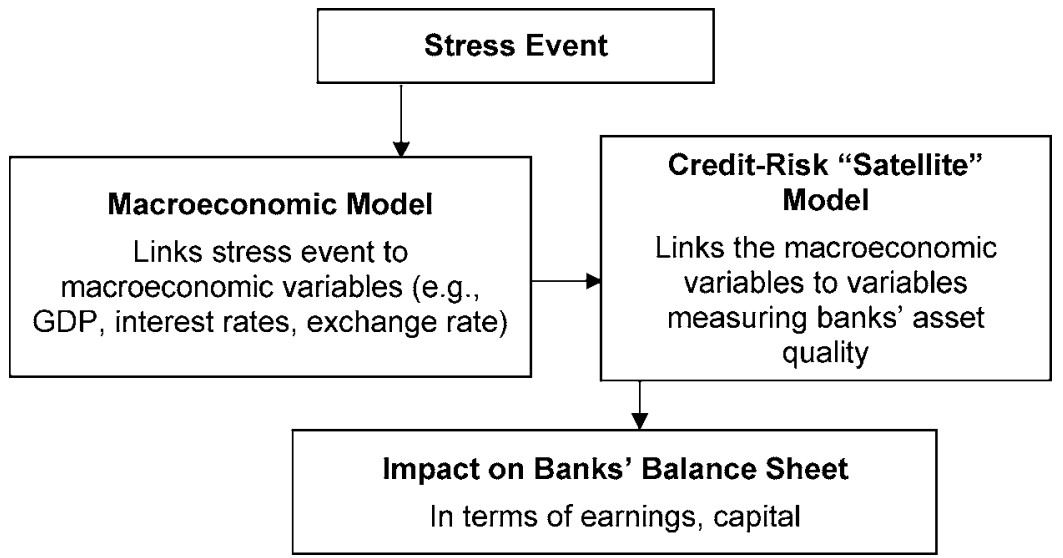

Notes: This figure is adapted from Čihák (2007). For an overview of a typical stress-testing process, see also Jones, Hilbers, and Slack (2004).

income and on funding costs. Losses are then compared with the buffers of profits and capital.

This approach has valuable strengths, but it also suffers from some important limitations. Generally, current models are weak in the treatment of key financial system interactions. For example, they only rarely model the impact of funding and market liquidity stresses or the correlation between credit, market, and liquidity risks. Feedback effects are often absent or modeled in rudimentary fashion. Existing methods are generally unable to endogenously account for cross-border transmission channels for risk, including cross-border contagion between financial institutions. They often ignore potential nonlinearities and structural breaks in estimated relationships. In addition, some approaches focus on a projected conditional mean stress scenario outcome and fail to consider the distribution of the losses that will be borne by individual financial institutions in a real-world stress situation. ${ }^{4}$

\footnotetext{
${ }^{4}$ The strengths and limitations of traditional stress tests were examined extensively at the ECB conference on "Simulating Financial Instability," Frankfurt, July $12-13,2007$.
} 
The market turmoil that began in mid-2007 in the U.S. "subprime" mortgage market has highlighted the crucial importance of the links between credit risk, funding liquidity risk, market risk, and counterparty credit risk, as well as other limitations of current stress tests. Addressing these limitations is therefore an important priority for both banks and financial stability authorities, as is shown by the recent initiatives undertaken by various international bodies. ${ }^{5}$ Some of the enhancements designed to overcome specific problems of traditional stress-testing techniques are addressed in the latest research projects initiated by the various agencies and are also reviewed in the following sections.

Table 1 summarizes the common stress-testing framework of the various agencies and classifies the models used in the different stages of the process according to their methodologies and assumptions.

\section{The Design of the Macroeconomic Stress Scenario}

In macro-scenario stress testing, the financial sector effects of multiple shocks to macroeconomic and financial variables are estimated using different models. The stress scenario's effects on macroeconomic conditions are typically measured using (i) a structural econometric model, (ii) vector autoregressive methods, and (iii) pure statistical approaches.

Many stress-testing approaches use an existing structural macroeconomic model (e.g., one used by the central bank for forecasts and policy analysis) to project the levels of key macroeconomic indicators under the stress conditions assumed. A set of initial shocks are taken as exogenous inputs, and their interactions with the other macroeconomic variables are projected over the scenario horizon. The simulations will produce a range of economic and financial variables as outputs, such as GDP, interest rates, the exchange rate, and other variables.

The use of structural models imposes consistency across predicted values in the stress scenario. Moreover, they may allow for endogenous policy reactions to the initial shock. The feasibility of

\footnotetext{
${ }^{5} \mathrm{As}$ for the work of the Basel Committee related on stress testing liquidity risk, see Basel Committee on Banking Supervision (2008).
} 
the approach for stress-scenario analysis varies with modeling expertise and the type of macro model. Some considerations involved in using a macro structural model are discussed in Jones, Hilbers, and Slack (2004), such as the choice of the baseline assumptions, the policy responses, the time horizon, and which variables are assumed fixed and which are shocked. Another frequently mentioned concern is the inability of linear models to capture relationships between macroeconomic variables that may become nonlinear at times of stress, as well as the difficulty in determining the likelihood of a specific macro scenario.

In the context of the FSAP exercise, all the authorities used the domestic macroeconomic models developed for monetary policy purposes. However, since a domestic model does not provide all the information that is needed when shocks arise from international linkages, in some cases the models were extended to incorporate international effects.

If a well-developed macroeconomic model is not available, or it is not considered feasible to generate consistent relevant shocks, a second possibility is vector autoregression (VAR) or vector errorcorrection models (VECMs). In these models, a set of macroeconomic variables are jointly affected by the initial shock, and the vector process is used to project the stress scenario's combined impact on this set of variables. VAR models have appeal because they are a flexible and relatively simple way of producing a set of mutually consistent shocks, although they do not include the economic structure that is incorporated in the macro modeling approach. ${ }^{6}$ As detailed in table 1 , these models are used in the studies developed at the central banks of the United Kingdom (BoE), Japan (BoJ), Spain $(\mathrm{BoS})$, and the Netherlands (DNB), and at the European Central Bank (ECB).

In its Financial System Report (Bank of Japan 2007), the BoJ estimates a VAR model comprising five macroeconomic variables (GDP, inflation rate, bank loans outstanding, effective exchange rate, and the overnight call rate). Van den End, Hoeberichts, and Tabbae (2006) and Jiménez and Mencía (2007) use a VAR structure

\footnotetext{
${ }^{6}$ As noted by Åsberg and Shahnazarian (2008), an important operational advantage of VAR models based on a few variables is that they do not require particularly substantial resources and their results are easy to interpret.
} 
to model the response to a shock of the two macroeconomic factors included in an auxiliary credit-risk model (see subsection 4.1). ${ }^{7}$ The model used by Castrén, Dées, and Zaher (2008) is a global vector autoregressive (GVAR) model based on country- or region-specific VECMs, where domestic and foreign variables interact simultaneously; the endogenous variables included in the country-specific models are real output, the rate of inflation, real equity prices, and short- and long-term interest rates. ${ }^{8}$ The BoE prototype model uses a two-country version of the GVAR approach, modeling the UK and U.S. economies only, with the same macroeconomic variables as in the ECB paper. ${ }^{9}$

For stress-testing purposes, the Norges Bank developed an "ad hoc" small macro model that is used to design extreme stress scenarios and follow the transmission of initial macro shocks through a set of micro-data-based models for the corporate, household, and bank sector. The macro model focuses on risks that originate and develop outside the financial system (the corporate and household sector, and asset prices). In particular, household credit is a function of housing prices, interest rate, and income; housing prices are determined by housing credit, interest rates, unemployment, income, housing stock, and expectations. The model includes feedback effects from housing prices and credit to GDP. ${ }^{10}$

\footnotetext{
${ }^{7}$ Van den End, Hoeberichts, and Tabbae (2006) also use a well-developed macro model (Norkmon/NIGEM) to simulate macro stress scenarios. The projected path of macro variables (GDP, interest rate) is subsequently used as input in an auxiliary VAR model (see section 4).

${ }^{8}$ The GVAR is a set of twenty-six $\operatorname{VAR}(2,1)$ models specific to twenty-five countries and one specific to the euro area. Each model includes a set of domestic/regional macroeconomic variables (usually five or six) and a vector of foreign variables specific to the respective country/region. In addition to the usual macro variables, the specification also includes the stock market return.

${ }^{9}$ In the BoE approach, the GVAR is a set of two VAR $(2,1)$ models, one for the United Kingdom and one for the United States; the United Kingdom is treated as a small open economy and the United States represents the rest of the world. The BoE approach (discussed in Haldane, Hall, and Pezzini 2007) models income, market, and credit risk jointly, as well as some key feedbacks across banks, such as network and market liquidity externalities; a prototype version of the model is described in Alessandri et al. (2007).

${ }^{10}$ See Andersen et al. (2008). Much emphasis is put on linking the different macro-micro models together as a system. The corporate sector model is designed to analyze the default probability of all Norwegian limited companies (see subsection 4.2). For a discussion of the feedback effects, see also section 4.
} 
In contrast to structural macroeconometric and VAR/VECM models, the Oesterreichische Nationalbank (OeNB), in its Systemic Risk Monitor (SRM), has developed a pure statistical approach to scenario design. ${ }^{11}$ Macroeconomic and financial variables are modeled through a multivariate t-copula. The copula approach has two important advantages. First, the marginal distributions can be different from the multivariate distribution that characterizes the joint behavior of the variables. Second, the co-dependence between the macro-financial variables displays tail dependence (i.e., "correlation" increases under stress scenarios). However, as a "purely" statistical approach, it is not as well suited for policy analysis. Drehmann (2008) underlies how important is the suitability for storytelling for a proper communication of policy evaluations and how using general equilibrium structural macroeconomic models may be appropriate in highlighting the key macroeconomic transmission channels from shocks to impact on credit risk. By contrast, risk managers at financial institutions are less interested in the unwinding of the transmission mechanism and are more focused on the model forecast performance, which can guide their day-to-day decision-making process (see the discussion in section 7 ).

\section{The Credit-Risk Models}

Both the structural econometric and the VAR approaches require a method to map macroeconomic variables into indicators that can be used to estimate the implications of the stress scenario for banks' balance sheets. Macroeconomic models, in fact, typically do not include a measure of credit risk, so the second stage of a stress-testing process usually involves estimating satellite or auxiliary models that link a measure of credit risk to the macroeconomic model variables, thus mapping external shocks onto banks' asset quality shocks.

In these credit-quality regression models, loan performance measures are typically related to measures of macroeconomic conditions. Blaschke et al. (2001) report an example in which the nonperforming loan (NPL) ratio is regressed against the nominal interest rate, the

\footnotetext{
${ }^{11} \mathrm{SRM}$ is a model developed by the Austrian central bank for systemic financial stability analysis and stress testing; the framework includes credit risk, market risk, and interbank contagion risk. See Boss et al. (2006).
} 
inflation rate, the change in real GDP, and the change in the terms of trade. The coefficients of the regression provide an estimate of the sensitivity of loan performance to those macroeconomic factors.

The assumption is that loan quality is sensitive to the economic cycle. The estimation strategy normally requires the selection of an initial set of macroeconomic and financial variables that, according to theory and empirical evidence, affect credit risk. Variables such as economic growth, unemployment, interest rates, equity prices, and corporate bond spreads contribute to default risk. In particular, interest rates are a crucial variable, as they represent the direct cost of borrowing. Among alternative specifications, the preferred one is selected on the basis of the consistency of macroeconomic variables with economic theory (that is, the variable's sign has to be "right"; otherwise, it is dropped) and on the specifications' goodness of fit. ${ }^{12}$

A satellite model that treats the macroeconomic variables as exogenous ignores - by construction - the feedback effects from a situation of distress in the banking system to the macro economy, which is one of the many limitations of traditional stress testing. Castrén, Dées, and Zaher (2008) argue that there are several possible reasons for this approach, such as a lack of sufficiently long timeseries data, more modeling flexibility, easiness of implementation, and interpretation. ${ }^{13}$

Unlike the macroeconomic model, the credit-risk satellite model can be estimated on data for individual banks and even individual borrowers. Various modeling techniques have been applied so far, mostly depending on data availability. Čihák (2007) divides approaches into two classes: one is based on data on loan

\footnotetext{
${ }^{12} \mathrm{~A}$ detailed description of such an estimation strategy is provided in Segoviano (2006).

${ }^{13}$ The analysis of feedback effects is a core concern for financial stability work, as the recent intensification of the financial crisis has aggravated the downside risks to growth. The typical econometric framework that allows for feedback effects between the financial sector and the real economy is the VAR methodology, in which a vector of endogenous variables includes both a measure of credit quality (or another proxy of financial distress) and aggregate economic variables associated with the state of the business cycle (see the discussion in Chan-Lau 2006). Two studies reviewed in this section actually apply this methodology: Marcucci and Quagliariello (2008), who explicitly address this issue, and Åsberg and Shahnazarian (2008), who discuss only the sensitivity of credit risk to shocks to the macroeconomic variables.
} 
performance, such as NPLs, loan loss provisions (LLPs), and historical default rates; the other is based on micro-level data related to the default risk of the household and/or the corporate sector. The same classification is used in this section, highlighting the distinct features of the different approaches. The capstone of many creditrisk satellite models is the estimation of the credit-portfolio loss distribution, which summarizes its overall risk profile and permits a thorough assessment of the impact of a shock (see section 6).

\subsection{Models Based on Loan Performance}

In this approach the key dependent variables are the NPL ratio, the LLP ratio, and historical default frequencies. As shown in table 1, these models include various macroeconomic factors, ranging in a number from two to five depending on the country. In some cases variables more directly related to the creditworthiness of firms are added, such as measures of indebtedness; in other cases, marketbased indicators of credit risk, such as equity prices and corporate bond spreads, are also used. ${ }^{14}$

As regards the level of aggregation, and depending on the availability of data, models based on loan performance data can be run at the aggregate level, at the industry level, or even at the level of the individual banks.

Alessandri et al. (2007) and Marcucci and Quagliariello (2008) model credit quality using observed default frequencies at the household/corporate level of aggregation. Aggregate data allow Marcucci and Quagliariello to use a VAR approach to estimate the satellite credit-risk model, whereas previously VAR models had been used in the first stage of the stress-testing process. ${ }^{15}$ Their model for the corporate sector includes the default rate and four macroeconomic variables (output gap, inflation, short-term interest rate, and real exchange rate). In the identification scheme, the default rate is assumed to be contemporaneously exogenous to the output gap

\footnotetext{
${ }^{14}$ Introducing market variables such as interest rates, foreign exchange rates, equity, and real estate price indices into credit-risk models is a way of explicitly integrating the analysis of market and credit risks.

${ }^{15}$ Åsberg and Shahnazarian (2008) also use a similar approach, estimating a VECM model (see subsection 4.2).
} 
and all the other macroeconomic variables. The impulse-response functions indicate significant impact of the various macroeconomic variables (except inflation) on the default rate.

The credit-risk models of Lehmann and Manz (2006), van den End, Hoeberichts, and Tabbae (2006), and the German Bundesbank (Deutsche Bundesbank 2006) use the LLP ratio to measure credit quality at the individual bank level, with static or dynamic panel data estimation. The panel estimation of individual banks' LLPs controls for individual bank characteristics that affect credit risk and captures the banks' different sensitivities to macroeconomic developments.

Jiménez and Mencía (2007), Fiori, Foglia, and Iannotti (2008), and the OeNB's SRM all model historical default rates grouped by industry. ${ }^{16}$ The sectoral breakdown allows the use of different macroeconomic variables to explain default frequencies in different industry sectors and the inclusion of sector-specific explanatory variables to improve the goodness of fit. For example, in the OeNB's SRM model, the number of statistically and economically most reasonable explanatory macroeconomic variables ranges from two to four depending on the sector, with some variables common to all the sectors. ${ }^{17}$

In such models, macroeconomic variables that are found to be significant for many sectors represent the systematic risk component; intersectoral default correlation is due to the common dependence on the systematic component. The idiosyncratic risk component is measured by potential sector-specific variables and/or by the residuals of the sectoral equations. When systematic risk is taken into account, default events should be independent, and the cross-equation residuals should be uncorrelated (conditional independence). If that is not the case, macroeconomic factors do not fully explain the default correlations across sectors; an important implication is that a portfolio's credit risk can be significantly underestimated (see discussion in section 7).

\footnotetext{
${ }^{16}$ In addition to ten industry equations, Jiménez and Mencía (2007) model one mortgage sector and a sector of consumer loans.

${ }^{17} \mathrm{GDP}$ or industrial production, the unemployment rate, investment in equipment, and the price of oil are significant in more than one sector; see Boss (2002) for an explanation of the model selection procedure.
} 
Jiménez and Mencía (2007) and Fiori, Foglia, and Iannotti (2008) argue that micro-contagion effects between sectors create an additional channel of default correlation. Using a different estimation strategy, both papers allow sectoral default frequencies to depend on macroeconomic conditions as well as on latent factors that can capture contagion effects. Accordingly, they are able to distinguish "cyclical" sectors (those highly sensitive to systematic risk) from those more dependent on idiosyncratic risk. Both studies find significant micro-contagion effects and similarly identify agriculture, manufacturing, construction, and trade as "cyclical" sectors, and mining and quarrying and utilities as "idiosyncratic." 18

The use of loan performance data to measure credit quality raises some important questions. Loan performance is a lagged or "retrospective" indicator of asset quality, in that it reflects past defaults. Loan loss provisioning rules may vary across jurisdictions, and legal protocols may determine whether or not institutions actually write off nonperforming loans or keep them on their financial statements with appropriate provisioning. Variations in loan loss provisions, in addition, may be only partly driven by changes in credit risk; other bank-specific factors, such as income-smoothing policies, might also come into play.

Another frequent problem in interpreting macroeconomic models of credit risk concerns the use of linear statistical models: the linear approximation may be reasonable when shocks are small, but when they are large, nonlinearities are likely to be important. In fact, almost all the studies reviewed here, following Wilson (1997), have used nonlinear specifications, such as the logit and probit transformation, to model the default rate. As van den End, Hoeberichts, and Tabbae (2006) argue, nonlinear transformations of the default rate extend the domain of the dependent variable to negative values and take into account the possible nonlinear relationships between macroeconomic variables and the default rate that are likely in stress situations.

\footnotetext{
${ }^{18}$ Latent factors are orthogonal to the observable macroeconomic conditions. Jiménez and Mencía (2007) use a Kalman filter to deal with the unobserved factors; Fiori, Foglia, and Iannotti (2008) use factor analysis to identify the latent factors that account for the contagion component.
} 
To address nonlinearities, the specification of the credit-risk model used in the macro stress-testing exercise of the Bank of Canada includes nonlinear terms. The model analyzes the relationship between a logit transformation of Canadian sectoral default rates and two macroeconomic variables (GDP and interest rate), adding higher-order terms as explanatory variables. ${ }^{19}$ It shows a better performance with respect to the same model without higherorder terms - in particular, in stressful periods, when the default rate reaches its historical peak; without nonlinearities, even the extreme shocks would have had a very limited impact on default rates.

\subsection{Models Based on Data for Individual Borrowers}

In this approach the credit-risk satellite model is estimated on individual borrower data. In this case, the model specification may also include macro-financial data as explanatory variables. When no macroeconomic variables are included, an additional satellite model may be used to link the macro-financial variables to borrower-specific data.

Using a database of yearly accounting data for all limited liability companies in Norway, Eklund, Larsen, and Bernhardsen (2001) relate the probability of default to borrower characteristics such as firm age, size, industry, and accounting variables measuring corporate earnings, liquidity, and financial strength. In this model, the projected figures for the main macroeconomic variables are used to estimate the future income statement and balance sheet of each company and on this basis to calculate individual probabilities of default (PDs). Data are then aggregated to estimate the banking sector's total loan loss.

Individual measures of credit quality can be exploited to estimate a direct relationship with macroeconomic variables. Åsberg and Shahnazarian (2008) and Castrén, Fitzpatrick, and Sydow (2008) use Moody's KMV expected default frequencies (EDFs) to model the average credit quality of listed companies. The EDF is a forwardlooking, market-based measure of credit risk that gauges a firm's

\footnotetext{
${ }^{19}$ The macro stress-testing exercise of the Bank of Canada is described in Coletti et al. (2008). The treatment of nonlinearities is discussed in Misina and Tessier (2008).
} 
probability of defaulting within a year, based on the volatility of its share price.

Åsberg and Shahnazarian (2008) analyze the median EDF of all Swedish nonfinancial listed companies and estimate a vector errorcorrection model (VECM) for this aggregate EDF and three macroeconomic variables (industrial production index, consumer price index, and short-term interest rate). Assuming a long-term correlation between variables, a VECM can discern shared trends between series as well as short-term fluctuations. The results indicate that the macroeconomic variable with the strongest (positive) impact on $\mathrm{EDF}$ is the interest rate, and that a fall in manufacturing output and an increase in inflation lead to a higher EDF. ${ }^{20}$

The model by Castrén, Fitzpatrick, and Sydow (2008) also measures credit risk by the median EDF of euro-area companies, but at the sector level (eight economic sectors). The model relates the credit quality of European companies to five macroeconomic variables, including real equity prices, measured for the whole euro area; the parameters are statistically significant and with the expected sign for real equity prices and, in four of the eight sectors, for GDP. $^{21}$

In contrast to the use of market-based measures of credit risk, the French Banking Commission (FBC) and the BoJ use internal data sets of individual nonfinancial company ratings, whose evolution over time is summarized by transition matrices. ${ }^{22}$ Both models estimate the sensitivity of a nonlinear transformation of the probability that borrowers will migrate to a different rating class with respect to

${ }^{20}$ Åsberg and Shahnazarian (2008) observe that higher inflation implies higher factor prices, which lead to increased costs and tend to impair credit quality. Moreover, high inflation is usually considered a signal of macroeconomic mismanagement and a source of uncertainty. Thus the relation between the default rate and the rate of inflation should be positive. However, higher inflation also implies higher product prices, which can boost earnings, and a lower debt burden in real terms, thereby improving creditworthiness.

${ }^{21}$ The fact that the interest rate is not significant may seem to be a counterintuitive result in view of its importance as a driver of corporate credit quality. The authors explain by reference to the characteristics of the dependent variable: the main drivers of EDFs are the value of asset/equity (market capitalization) and the default point (which is a function of liabilities), so it is not surprising that the econometric analysis confirms the role of equity prices and not of interest rates.

${ }^{22}$ See Commission Bancaire (2007) and Bank of Japan (2007). 
a limited number of macroeconomic variables. ${ }^{23}$ In the FBC model, the macroeconomic variables are GDP and short-term and long-term interest rates. In the BoJ model, a system of five equations (one for each rating class) is estimated by seemingly unrelated regression to account for possible correlations between error terms. Explanatory variables are GDP growth rate and a leverage ratio as proxies of profit and liability conditions. GDP is significant in all but the lowest rating class; the results for the debt ratio are more mixed.

In sum, the survey shows a wide array of approaches to credit-risk modeling in terms of measures of credit quality, level of aggregation, and estimation methodology. Methods that use current financial market data to predict bankruptcies (as contrasted with modeling LLPs or NPLs) within a given time horizon may be able to detect problems in the loan portfolio earlier than those based on loan classification data. Such methods, however, are restricted to listed companies and so may not be readily applicable in some countries. A common feature is that the macroeconomic variables used as explanatory variables are not numerous. As for the level of aggregation, models based on individual data can in principle lead to more accurate results; if these data are not available, there can still be benefits associated with parsimonious models using more aggregate data, as noted by Åsberg and Shahnazarian (2008).

\section{Stress-Test Implementation}

In the third stage of a typical stress-testing process, the macroeconomic models (structural, vector autoregressive, or purely statistical) are used to project the values of the macroeconomic variables under stress conditions and are applied in an auxiliary model of credit risk to estimate credit quality under stress.

As noted, all the authorities reviewed used a macroeconometric structural model for the FSAP exercises. In the Italian FSAP, one macroeconomic scenario involved a shock to oil and share prices. The effects on domestic macroeconomic variables were simulated using the Bank of Italy quarterly macroeconometric model to generate deviations from a baseline projection over several time horizons.

\footnotetext{
${ }^{23}$ In the BoJ model, the banks' borrower classification data available at the central bank were supplemented with credit scores provided by a Japanese rating agency.
} 
The macroeconomic projections for output gap and short-term interest rate were used in the credit-risk model to calculate an aftershock $\mathrm{PD}$; the result was an estimated increase of 83 percent.

In such an approach, however, the structural macroeconomic model generates point estimates associated with a single future path, the conditional mean path under the stress scenario, with no probabilistic interpretation.

The VAR/VECM framework can generate stress scenarios that do allow for probabilistic interpretations. Shock sizes are specified in terms of the unconditional standard deviation of the innovation in an autoregressive series, and under a normality assumption they can be given a probabilistic interpretation. Thus scenarios do not follow from the economic reasoning behind a structural macro model but are based only on a probabilistic method. Tail outcomes of such simulations present extreme scenarios.

Pesaran et al. (2006) were the first to present a VAR model to generate a probabilistic scenario for credit-risk analysis. Impulseresponse functions are used to examine how an isolated shock to one macroeconomic variable affects all the others. Impulse-response functions assume that the other variables are displaced according to their historical covariances with the variable being shocked, so that the correlations across shocks are accounted for in an appropriate manner. The authors examine the impact on a hypothetical corporate loan portfolio and its exposure to a range of macroeconomic shocks. For example, they find that a -2.33-standard-deviation drop in real U.S. equity prices causes an expected loss of 80 basis points over four quarters. This approach is particularly valuable in addressing specific risk-management questions and, in particular, producing a rank order of the possible shock scenarios.

Examples of scenarios generated by this probabilistic method are given in the stress exercises conducted at the BoJ and in Jiménez and Mencía (2007) and Castrén, Fitzpatrick, and Sydow (2008). In the BoJ model, the stress test assesses the impact of a negative GDP shock of a size that has a 1 percent probability. Jiménez and Mencía (2007) apply a three-standard-deviation shock to the GDP and interest rate variables; similarly, Castrén, Fitzpatrick, and Sydow (2008) use a five-standard-deviation shock for one macroeconomic variable of the GVAR model.

The OeNB's SRM multivariate t-copula approach is used to draw risk-factor changes randomly according to their estimated 
multivariate distribution. During the scenario simulation, one or more of the factor changes are set to a fixed value according to the given shock; changes for all other (nonstressed) risk factors are drawn from the conditional distribution given the stress scenario. For example, the SRM model documentation evaluates the impact of a drop in GDP or of a rise in interest rates; the t-copula approach ensures consistency with the overall dependency structure between risk factors. ${ }^{24}$

Van den End, Hoeberichts, and Tabbae (2006) propose an alternative method that accounts for simultaneous changes in the macroeconomic variables and their interactions as typically present in the macro scenarios derived from structural macro models. To simulate the hypothetical stress scenario, the projected values of the macroeconomic factors are used to reestimate a VAR model including GDP and interest rate. Reestimating a VAR that includes stressed values for the macroeconomic factors can take into account changes in the correlations and overcome the objection that stress-testing models posit constant statistical relationships, which might not be the case in stress situations.

A similar procedure is applied in the paper by Asberg and Shahnazarian (2008): they use the impulse responses of the Riksbank's macroeconometric model to a given shock (e.g., a supply shock) to estimate stressed values for the three macroeconomic variables of a VEC model that also include EDFs (see section 4.2). The VEC model is then used to forecast the stressed EDFs conditional on the stressed values of the macroeconomic variables.

\section{Impact Measures}

The final step in the stress-testing process is evaluating the impact on the banks' loan portfolio and judging whether banks can withstand the shock assumed. This means comparing the loss with an appropriate benchmark. Issues that arise concern the choice of the variable to measure the banking systems' ability to face shocks, the estimation of a loan portfolio's loss distribution, and the assessment of the impact for the systemwide portfolio as well as at the level of individual banks.

\footnotetext{
${ }^{24}$ The model can also simulate the effect of one single-factor shock (unconditional simulation). See Boss et al. (2006).
} 
Depending on the credit-risk model used, the results of the simulation can be expressed in terms of either provisions or projected default rates. In the latter case, given a (usually ad hoc) figure for the recovery rate, one can estimate banks' expected losses, which determines the volume of provisions to be set aside. As observed in Čihák (2007), in a normal situation ("baseline scenario"), banks would typically be profitable. When carrying out stress tests, it is important to evaluate impacts against such a baseline, as banks would exhaust profits before undergoing reductions in their balance-sheet or regulatory capital position. Expressing shocks only in terms of capital may result in overestimating the actual impacts if banks remain profitable in the baseline scenario. However, to accommodate the view that it is prudent to disregard profits, one can measure losses directly against capital or capitalization (capital or equity to assets, or capital to risk-weighted assets). The effects on capital adequacy ratios are obviously particularly important for agencies with supervisory responsibilities.

An important extension to the typical stress-test process focuses specifically on the impact measure. Instead of producing accounting measures of distress as point estimates under the assumed stress scenarios, more recent work has sought to derive a profit and loss distribution for the loan portfolio of the banking system as a whole, extending to systemwide scale the risk-management framework adopted at a micro level by many financial institutions in their risk-management systems.

The loss distribution shows the probability of loan losses of various sizes - from the possibility of no losses occurring to the loss of the entire loan portfolio. The expected loss - the mean of the distribution - is normally covered by earnings; banks need to hold a capital buffer to cover losses above those expected (unexpected loss or value-at-risk). ${ }^{25}$ The estimation of a loss distribution for the banking system's loan portfolio makes it possible to calculate the size of the aggregate capital buffer given a tolerance level (the economic capital).

\footnotetext{
${ }^{25}$ The shape of the loss distribution of a given portfolio is to a large extent determined by the presence of name concentration and/or correlations between the different exposures/sectors. The shape is typically skewed and has a relatively fat right tail, indicating that, although losses less than or around the expected value are most frequent, more extreme outcomes may also occur.
} 
In the context of a loan loss distribution, the stress exercise can be couched in terms of deterministic shifts in the parameters, such as the PD and the loss given default (LGD), as, for instance, the sensitivity analyses reported in Sveriges Riksbank (2006). Alternatively, macro stress scenarios like those discussed in section 3 can be used to simulate adverse macroeconomic conditions that-using the satellite models described in section 4-generate a stressed aggregate $\mathrm{PD}$ or a set of stressed sectoral PDs. Via this link, the stress test has a clear economic interpretation.

The idea of measuring the impact of credit shocks in terms of an overall systemwide credit loss distribution-as opposed to banks' expected losses - was first discussed in Sorge and Virolainen (2006) and applied in the OeNB's SRM stress-test model. ${ }^{26}$ Research projects along these lines are planned or under way at many authorities, with a view to improving the existing framework.

In a first approach, used in van den End, Hoeberichts, and Tabbae (2006), Alessandri et al. (2007), and Jiménez and Mencía (2007), the portfolio loss distribution is estimated using Monte Carlo simulation techniques, taking random draws of the innovations in the macroeconomic factors (GDP, interest rates, etc.). ${ }^{27}$ The estimation can be performed at the aggregate level for the banking system or for individual banks.

In a second approach, used by the Sveriges Riksbank (2006), by Castrén, Fitzpatrick, and Sydow (2008), and in the OeNB's SRM, the simulation of random innovations in the macroeconomic factors is supplemented with a readily available portfolio model, such as Credit Risk Plus. The use of a full-blown portfolio model can combine predictions on default frequencies with more granular information on the credit quality of individual borrowers.

The OeNB's SRM calculates a loss distribution using a modified version of Credit Risk Plus. Sectoral default frequencies from the model are combined with individual borrowers' default probabilities from the central credit register by adapting the latter according to the difference with the model-predicted default frequencies.

\footnotetext{
${ }^{26} \mathrm{~A}$ similar analysis is conducted also in Pesaran et al. (2006).

${ }^{27}$ In the paper by Jiménez and Mencía (2007), the simulation also includes random draws of the innovations in the latent factors; the BoE's model combines various sources of risk (see footnote 9) and the corresponding output is a distribution of total banks' assets rather than pure credit losses.
} 
If, for example, the model-predicted default frequency doubles due to changes in macroeconomic variables, this will result in a doubling of default probabilities of individual borrowers, which is then used to calculate the overall credit loss distribution using Credit Risk Plus.

A similar but simpler procedure is used by Castrén, Fitzpatrick, and Sydow (2008) and by the Riksbank. Instead of using individual default probabilities, both studies make assumptions about the creditworthiness of borrowers and classify loan portfolios into three quality classes; aggregate Moody's KMV EDFs of the lower and higher credit quality portions of the portfolio are adjusted accordingly.

Moving from a baseline to a stress scenario is likely to produce a shift in the conditional loss distribution and in the corresponding value-at-risk measure; in order to assess whether the banking system can withstand the assumed shock, the stressed value-at-risk (economic capital) should then be compared with a measure of actual capital held for credit risk by the banking system.

As is noted by Bonti et al. (2006), stress tests performed within a portfolio credit-risk model enable one to assess the outcomes of a stress scenario consistently with the quantitative framework used in a normal, nonstressed situation, because the stress scenario is translated into movements of "internal" risk drivers (the macroeconomic risk factors). The risk measures of the model (expected loss, valueat-risk) can be studied relative to the baseline simulation derived from the unconditional (nonstressed) risk-factor distribution. Using the same quantitative framework for normal and stressed situations implies that the relationships between nonstressed risk factors remain intact and the experience gained in the day-to-day use of the model can be used to interpret the results from stress testing. ${ }^{28}$

Finally, depending on the availability of micro data, it is important that central banks and supervision authorities calculate the impact at the individual bank level and not only for an aggregate systemwide portfolio. In fact, seeing the distribution throughout the system is essential to assessing the threat of contagion and the possible impact of confidence effects on stability.

\footnotetext{
${ }^{28}$ Consistency is one of the desirable properties of stress testing mentioned also in a Basel Committee study on credit-risk concentration (Basel Committee on Banking Supervision 2006).
} 


\section{Discussion and Evaluations}

This section discusses the main findings of the survey, highlighting a number of methodological issues that may be relevant to supervisors in reviewing stress-testing requirements under Basel II. From a financial stability perspective, the discussion contributes to the ongoing macroprudential research efforts to integrate macroeconomic oversight and prudential supervision, by facilitating early detection of key vulnerabilities and the assessment of macro-financial linkages.

\subsection{Characteristics of the Credit-Risk Models}

One application of the macro credit-risk models is the calculation of IRB capital requirements in stress scenarios: the impact of a macro stress scenario on regulatory capital can be evaluated by recalculating the Basel II formula with the stressed PDs from the credit-risk model. The models surveyed here differ significantly in such areas as the measure of credit quality chosen, the level of aggregation, and the estimation methodology.

- Borrower credit quality is modeled either on the basis of loan performance data, requiring time-series data on different proxies for default rates (such as NPLs or LLPs), or on the basis of market-based indicators (such as Moody's KMV EDFs). The use of different variables raises several issues that must be considered in interpreting the results. For example, loan performance is a "retrospective" indicator of asset quality: loan loss provisioning rules or policies may affect the financial statement data that are used. Market-based indicators, on the other hand, are fully reliable only for listed firms. Moreover, the magnitude and statistical significance of the relevant macroeconomic variables' estimated coefficients may differ with the indicator of credit quality.

- The studies reviewed here use different levels of aggregation for the dependent variable. Whenever possible, disaggregated data are essential to capture the differing response of sectors/banks/portfolios to stress scenarios. One major shortcoming of econometric models based on aggregate data is that the conditional means may conceal significant variation at the portfolio or bank level. More specifically, this 
procedure fails to detect uncertainty about (variations in) the actual defaults at the level of the single sector, bank, or individual obligor. Thus, the loss distribution obtained (see below) is more concentrated than the underlying overall loss distribution and so misses information about the extreme tails.

- The survey shows the importance of the model development stage, i.e., the statistical model-building technique. In general, a parsimonious selection of uncorrelated (or weakly correlated), statistically significant, and intuitively understandable variables makes the model more attractive for stress testing. In particular, economic plausibility is a key requirement in all the models: the economic meaning of the macroeconomic factors used must be clear, with no counterintuitive relationships with the dependent variable.

- The most important aspect in assessing the model specification process is overall performance in sample and out of sample. A common feature of macroeconometric-based models of credit risk is that macroeconomic variables alone tend to explain a fairly small part of the variation of the dependent variable, especially when only one or two macroeconomic variables are considered (omitted variables). The goodness of fit is considerably improved by the inclusion of latent variables (unobserved common factors), possibly accounting for microcontagion effects. Failing to include such variables can result in significant underestimation of tail risk.

- Other important aspects to emerge from our examination of the model specification process include (i) the model's ability to handle low-quality data (missing values, outliers, structural breaks), (ii) the time period used for calibration, which should span at least one full business cycle to ensure capturing the cyclical effects on default probabilities, and (iii) an evaluation of parameter stability and model robustness.

\subsection{The Formulation of Stress Scenarios and Stress-Test Methods}

The models used to simulate macroeconomic scenarios range from more structural methods, which are better suited for policy analysis, to pure statistical methods that model the multivariate distribution 
of macro-financial variables using nonlinear dependence structures (e.g., based on multivariate copulas). An intermediate option consists of reduced-form models such as VAR or VECM, which retain some of the desirable policy-analysis features of a structural model combined with some of the flexibility of a more statistical approach. However, macro models are generally local approximations of equilibrium relationships. They are not necessarily suitable for assessing the effect of large shocks, which are very likely to produce nonlinearities and regime shifts. This results in uncertainty over the size (and sometimes the sign) of the response. Whichever model is chosen, it is essential that the stressed macroeconomic variables be internally consistent.

So far, financial institutions have had trouble selecting "big picture" macroeconomic scenarios and have preferred to calibrate shocks directly in terms of micro variables. For individual firms, therefore, models such as VAR or VECM based on just a few variables can be feasible for designing internally consistent macroeconomic scenarios in a simple and transparent way and conducting macro stress tests without requiring particularly substantial resources.

\subsection{Impact Measures and the Estimation of a Loss Distribution}

While early stress-testing exercises concentrated mostly on expected losses, most of the recent methodologies estimate the entire portfolio loss distribution.

The loss distribution provides a measure of the credit VaR (economic capital or capital at risk) as well as other measures of "tail risk" under stress. In particular, the shape of the right-hand tail of the portfolio loss distribution is to a large extent dependent on key risk factors such as portfolio concentration and on correlations between risk components (PD, LGD, and exposure-at-default, EAD), which are not captured by other risk metrics such as expected losses. Stressed loss distributions can be used to examine stress scenarios in a consistent setting, and in particular to evaluate the future capital needs of banks to comply with their economic capital constraints under stress conditions, as required in the more general Pillar II stress test. 
The survey found basically two approaches to estimating credit loss distributions in the context of a macroeconomic multifactor credit-risk model. A first approach applies only Monte Carlo simulations of innovations in macroeconomic factors to obtain stressed aggregate or sectoral PDs. This implies (i) treating every loan in the estimation bucket (aggregate or sector) as equally risky regardless of the credit quality of individual borrowers and (ii) assuming that realized losses are always equal to expected losses or else that banks hold an infinitely granular portfolio. This would result in an underestimation of risk. ${ }^{29}$ In a second approach, the simulation of random innovations of the macroeconomic factors is supplemented with a full-blown portfolio credit-risk model, which generates loss distributions with greater variance and fatter tails.

In estimating the baseline and stressed loss distributions, much attention has been given to modeling default rates; there has not been much progress in modeling LGDs and EADs, and in most cases, ad hoc values for LGDs are assumed (e.g., LGDs and EADs are typically kept constant). However, in stressed scenarios, PDs often increase as the financial strength of households and firms deteriorates, LGDs increase as recovery rates fall with asset prices, and EADs increase as credit lines are drawn on in worsening financial conditions. Ignoring these correlations among PDs, LGDs, and EADs can result in a considerable underestimation of tail losses. It is accordingly important to model the joint behavior of these three variables in stress scenarios, as their correlations tend to increase in stress conditions.

\section{Concluding Remarks}

This paper reviews the quantitative methods developed at selected central banks and supervision authorities for stress testing credit risk. The focus is on macro stress testing - i.e., the linkage of the macroeconomic drivers of stress with bank-specific measures of credit risk - with a view to helping supervisors in reviewing stress tests for compliance with Basel II and contributing to the ongoing

\footnotetext{
${ }^{29}$ For the first remark, see Boss et al. (2006); for the second, see Alessandri et al. (2007).
} 
research efforts to integrate macroeconomic oversight and prudential supervision.

As a result of the IMF's Financial Sector Assessment Programs, central banks have acquired specific modeling expertise in this sector. The review shows the modeling and organizational complexity of macro stress testing, which involves a number of stages. The first step is to design a coherent macroeconomic stress scenario that is consistent with the application of a macroeconometric model. The second step, since these models generally do not include the financial sector, is to apply "satellite" models to measure credit risk, mapping the macroeconomic variables onto some measures of banks' asset quality. The third step is the assessment of losses under stress scenarios, evaluating them in connection with variables that gauge the banking system's ability to withstand shocks.

The paper outlines and compares features of the approaches adopted at the various authorities and traces the latest developments. In particular, (i) in devising scenarios, central bank researchers increasingly adopt models that are more flexible and easier to use, such as VARs and other strictly statistical rather than structural models; (ii) the "satellite" models for credit risk display a great variety of statistical methods, dependent variables, and levels of aggregation, while the explanatory variables are more uniform and not numerous; the most recent models, when data are available, incline toward a sectoral aggregation, which permits distinguishing between cyclical and acyclical sectors; and (iii) unlike the early macro stress testing, which assessed the impact of stress scenarios on expected losses, current research projects tend to envisage an assessment of the entire portfolio loss distribution and unexpected losses under stress conditions.

Finally, the paper analyzes and discusses a series of methodological aspects with a view to improving macro stress-testing models. A number of research programs are working to overcome some of these limitations. In particular, the current objectives are to extend time horizons and to build in banks' management actions to adjust balance sheets in response to the stress scenarios (for example, by changing lending and borrowing policy). In this way it would be possible to take account of the potential transmission, and amplification, of a shock within the financial system to the real economy. 


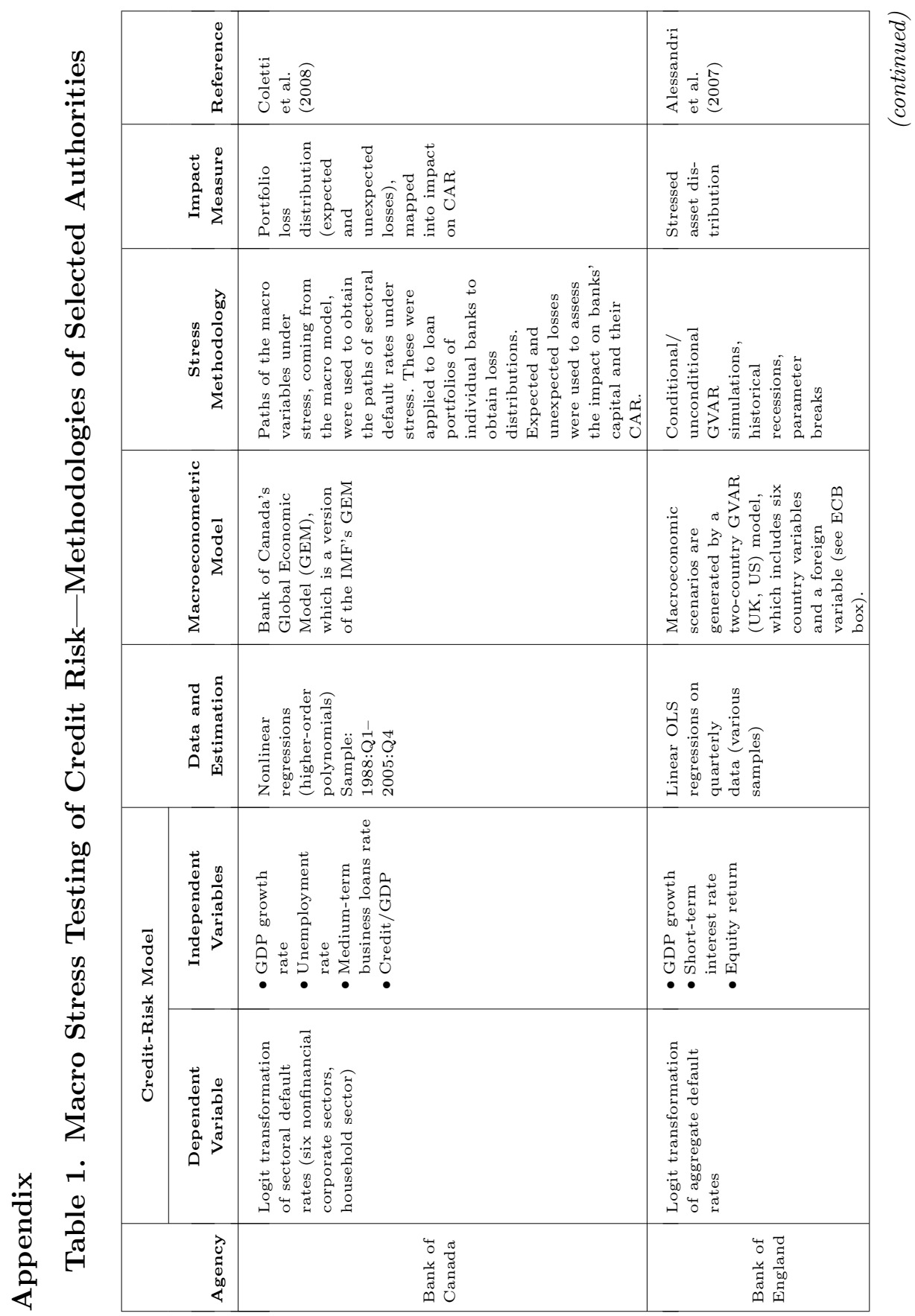




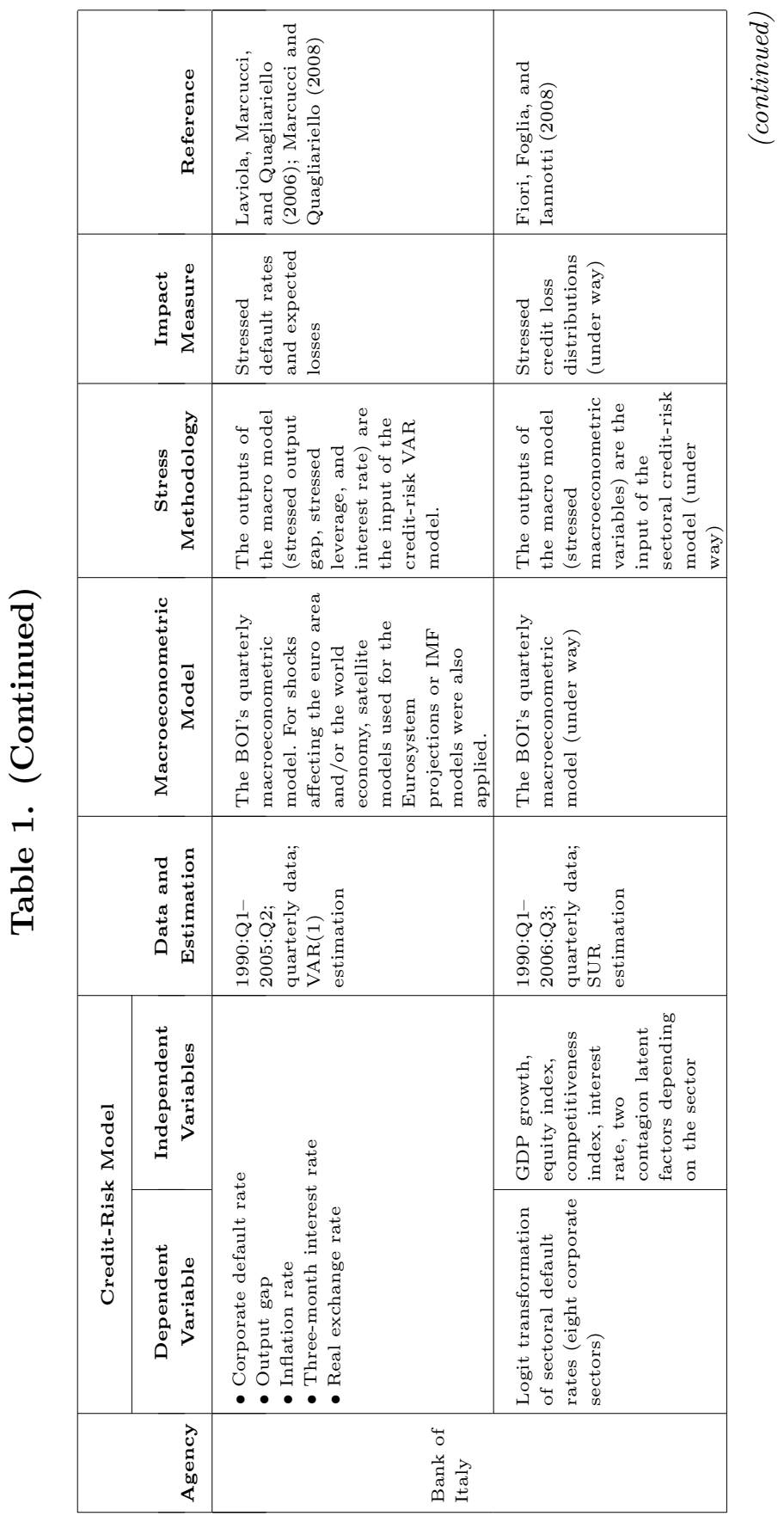




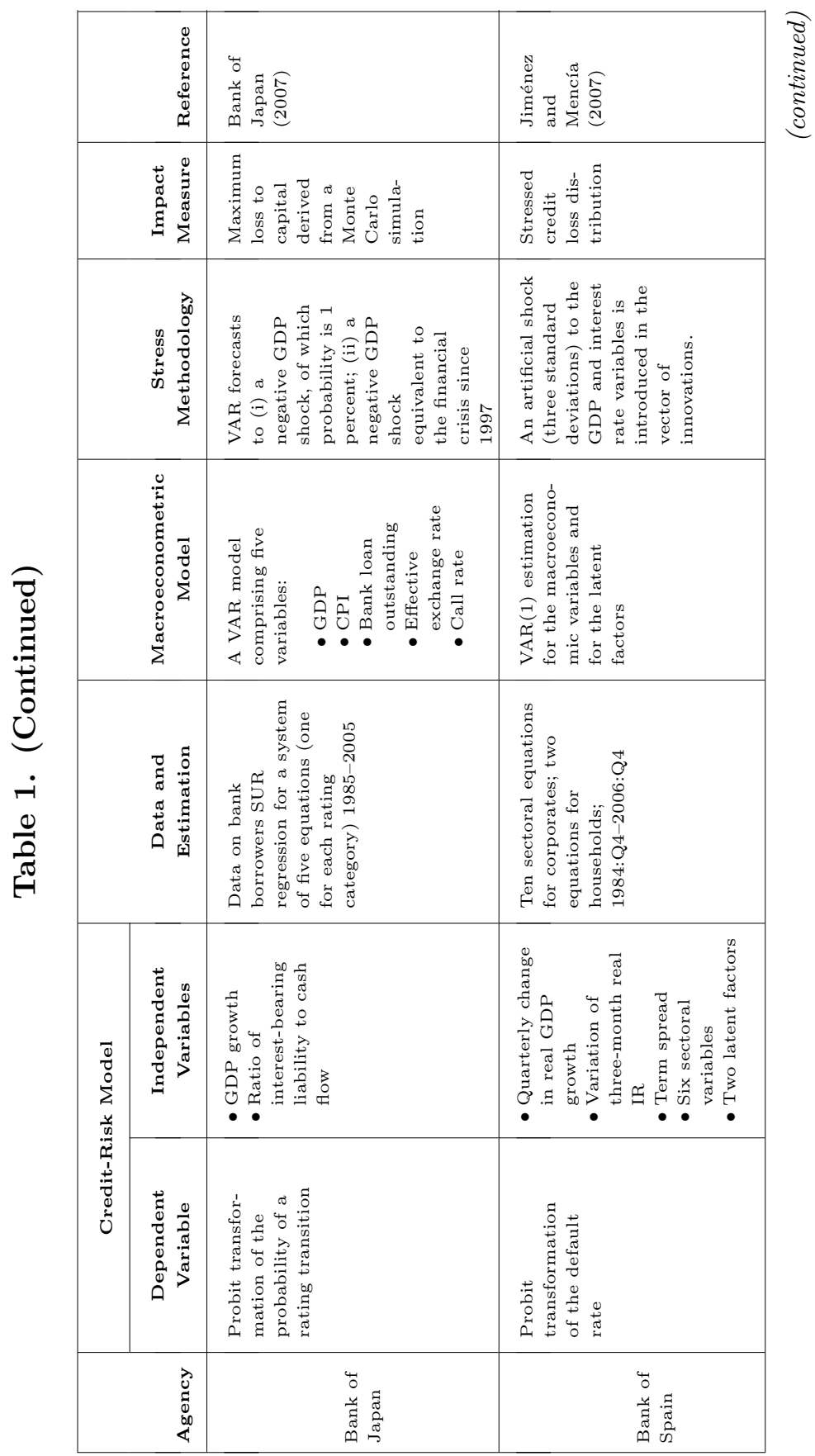




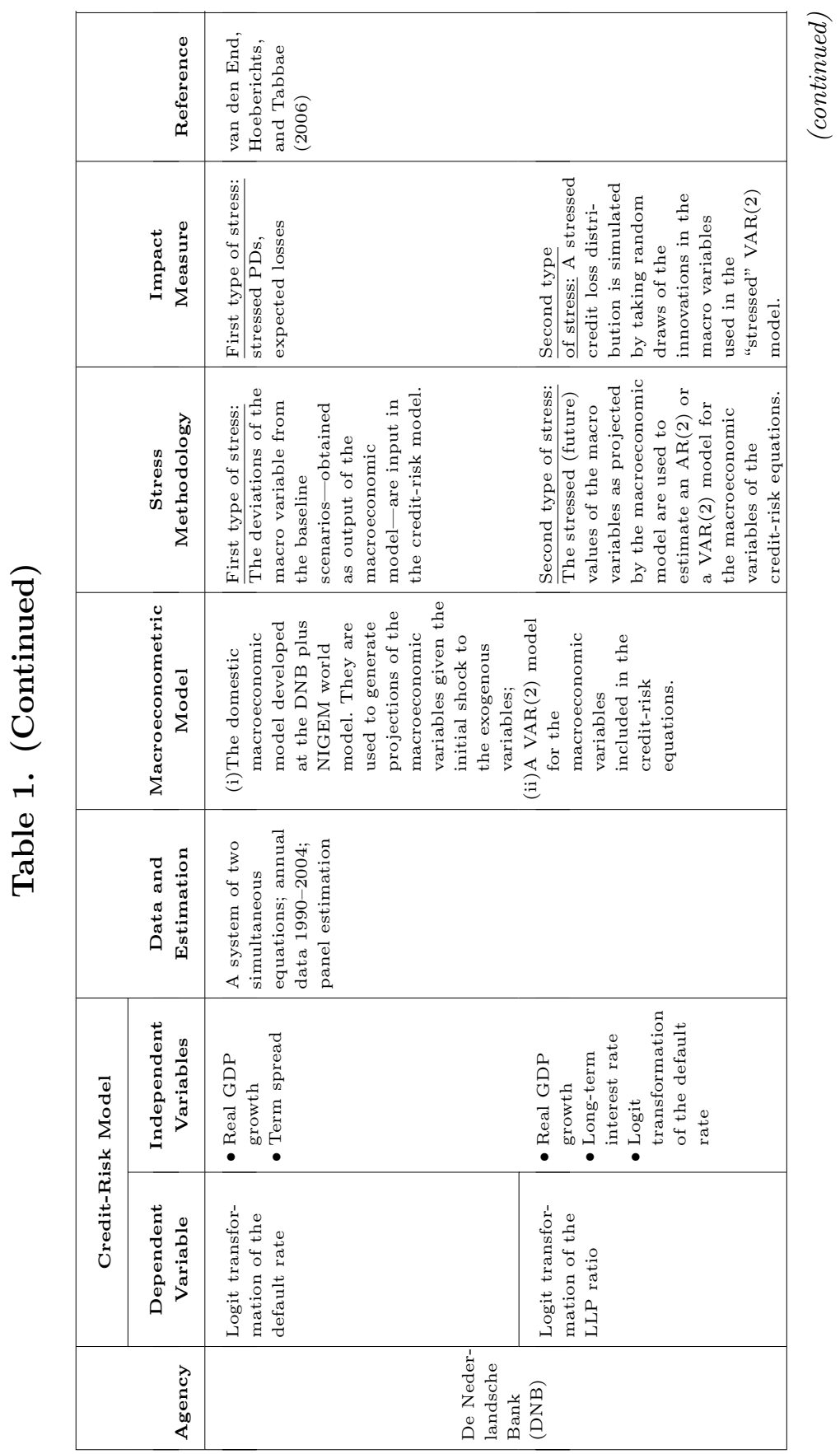




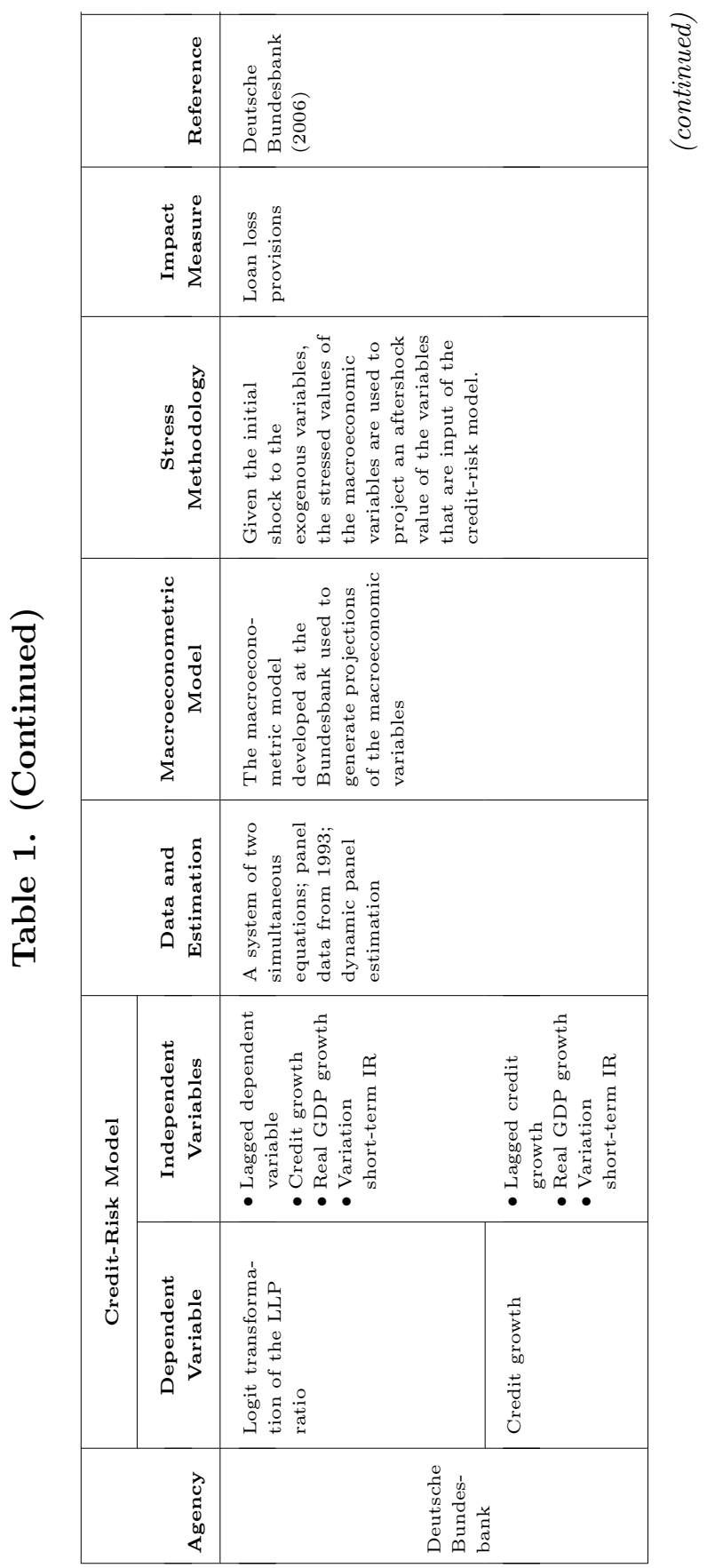




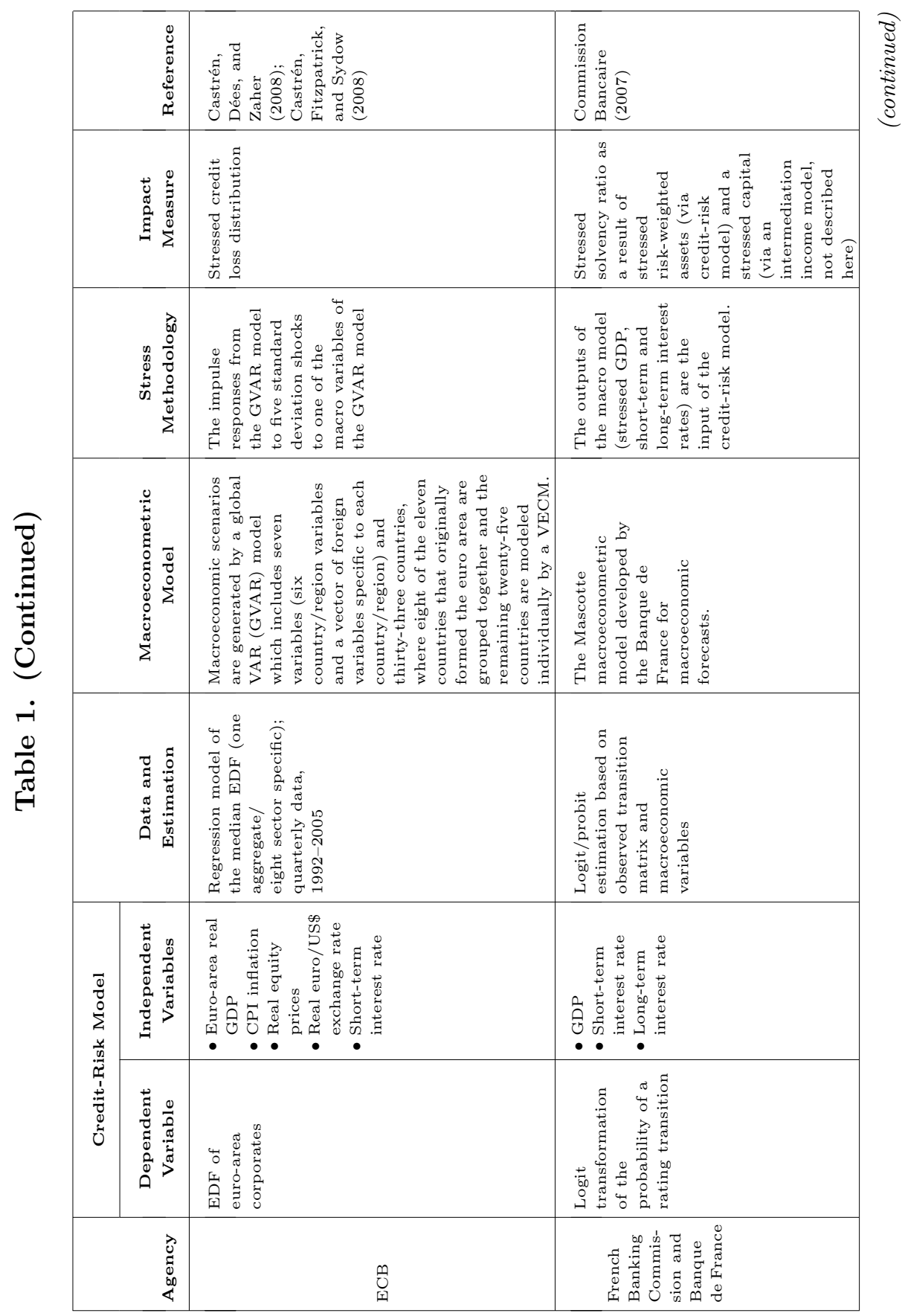




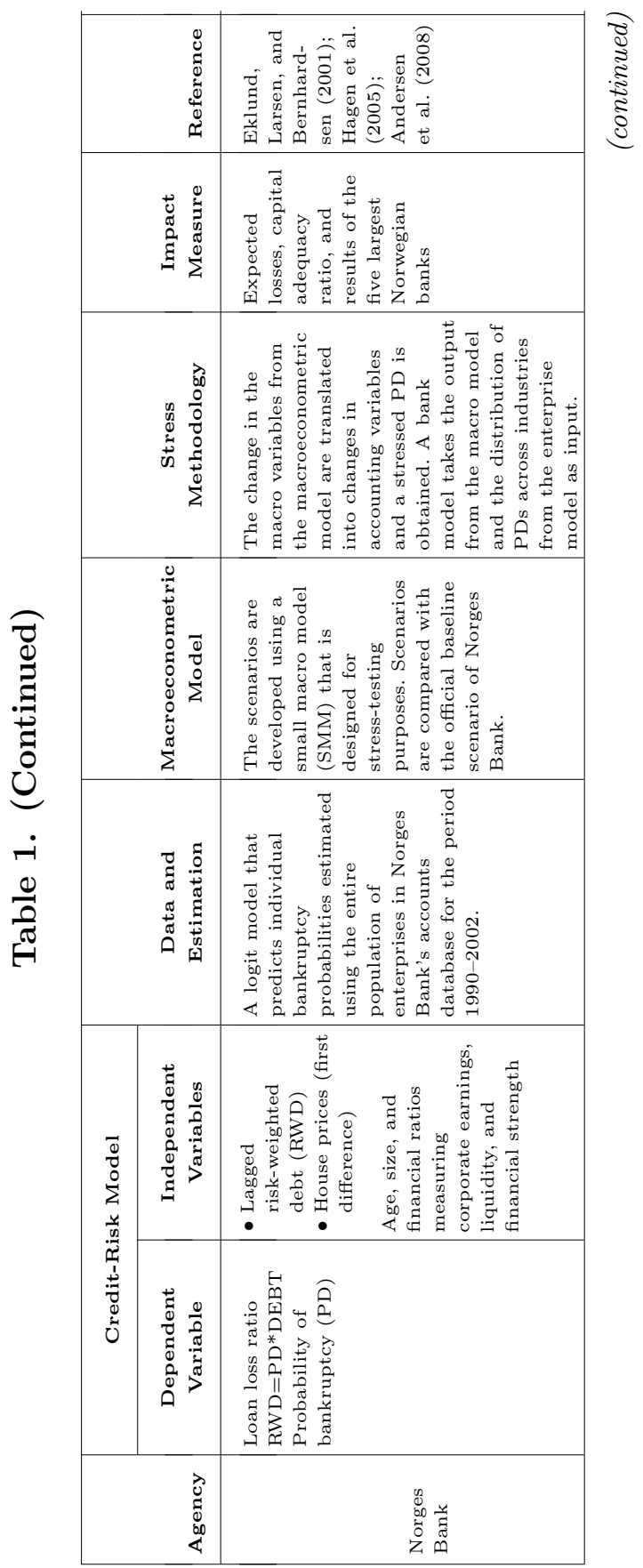




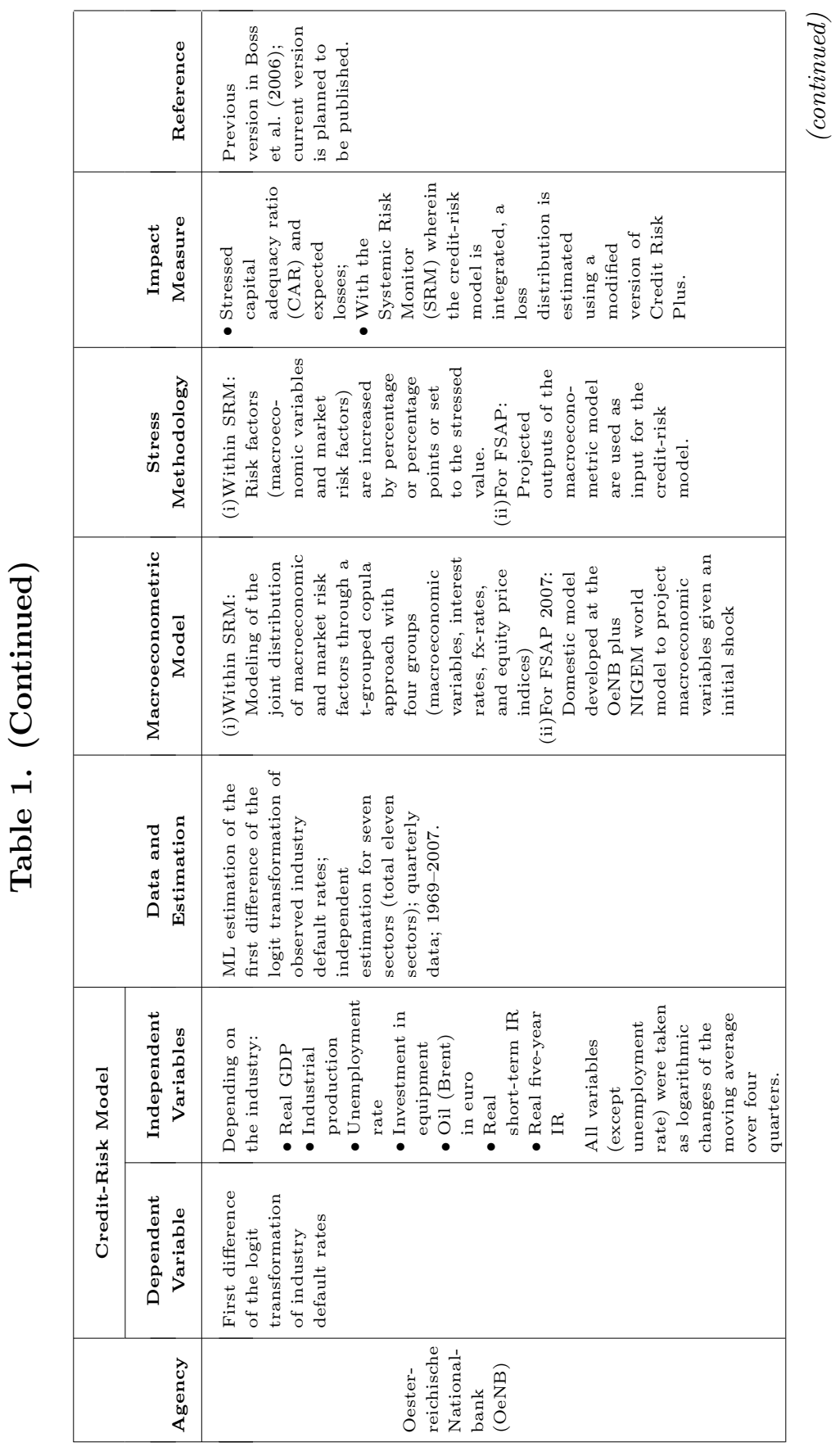




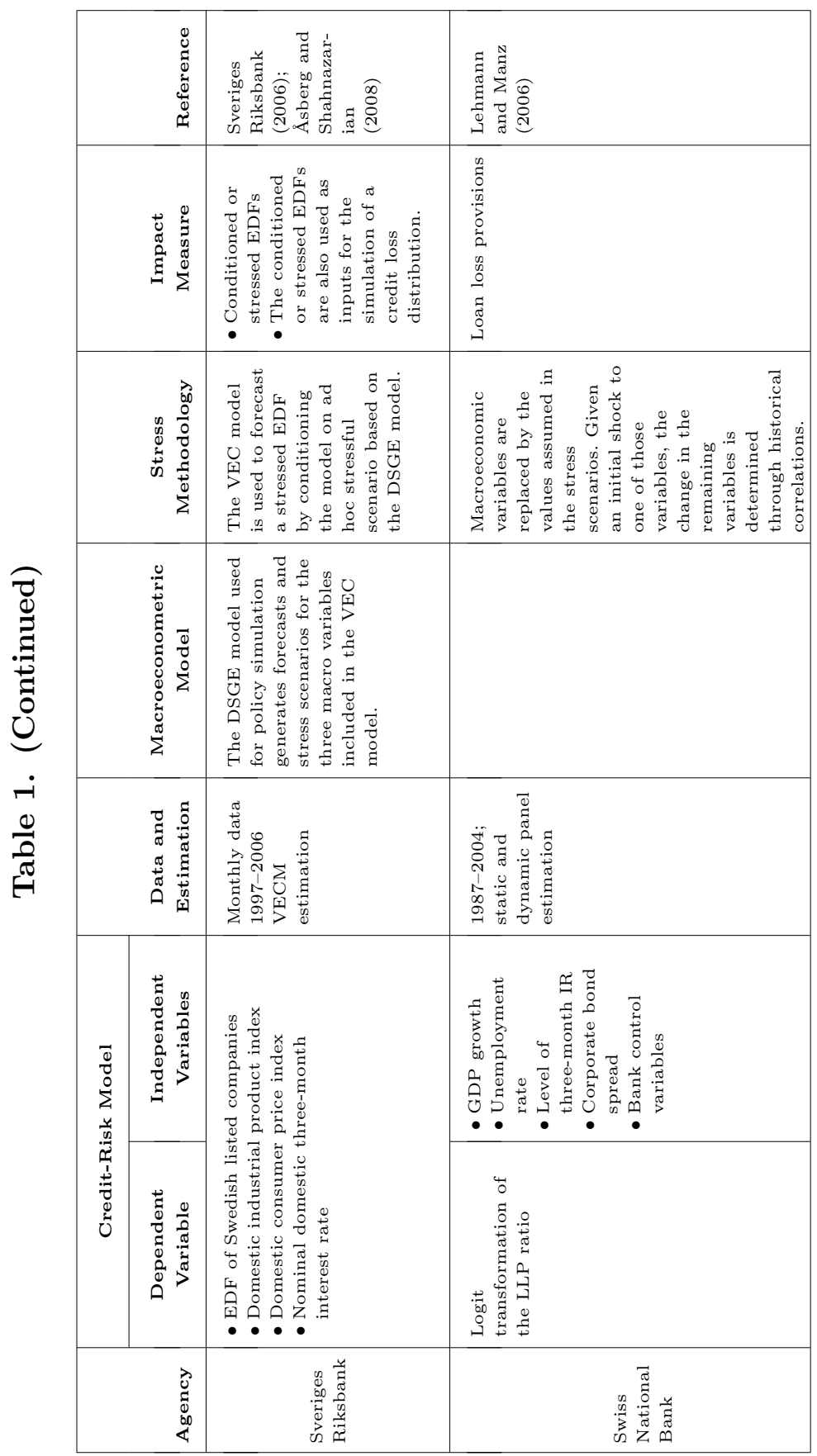




\section{References}

Alessandri, P., P. Gai, S. Kapadia, N. Mora, and C. Puhr. 2007. "A Framework for Quantifying Systemic Stability." (December). Preliminary paper presented at the workshop "Stress Testing of Credit Risk Portfolios: The Link between Macro and Micro," hosted by the BCBS and the DNB, Amsterdam, March 7, 2008. Andersen, H., T. O. Berge, E. Bernhardsen, K.-G. Lindquist, and B. H. Vatne. 2008. "A Suite-of-Models Approach to Stress-Testing Financial Stability." Staff Memo No. 2, Norges Bank.

Åsberg, P., and H. Shahnazarian. 2008. "Macroeconomic Impact on Expected Default Frequency." Sveriges Riksbank Working Paper No. 219 (January).

Bank of Japan. 2007. "The Framework for Macro Stress-Testing of Credit Risk: Incorporating Transition in Borrower Classifications." Financial System Report (September).

Basel Committee on Banking Supervision. 2005. "International Convergence of Capital Measurement and Capital Standards: A Revised Framework." (November). - 2006. "Studies on Credit Risk Concentration." BCBS Working Paper No. 15 (November). . 2008. "Liquidity Risk: Management and Supervisory Challenges." (February).

Blaschke, W., M. T. Jones, G. Majnoni, and M. S. Martinez Peria. 2001. "Stress Testing of Financial Systems: An Overview of Issues, Methodologies, and FSAP Experiences." IMF Working Paper No. 88.

Bonti, G., M. Kalkbrener, C. Lotz, and G. Stahl. 2006. "Credit Risk Concentrations under Stress." Journal of Credit Risk 2 (3): $115-36$.

Boss, M. 2002. "A Macroeconomic Credit Risk Model for Stress

Testing the Austrian Credit Portfolio." Financial Stability Report (Oesterreichische Nationalbank) 4: 64-82.

Boss, M., T. Breuer, H. Elsinger, G. Krenn, A. Lehar, C. Puhr, and M. Summer. 2006. "Systemic Risk Monitor: A Model for Systemic Risk Analysis and Stress Testing of Banking Systems." Internal Technical Document, Oesterreichische Nationalbank.

Castrén, O., S. Dées, and F. Zaher. 2008. "Global Macro-financial Shocks and Expected Default Frequencies in the Euro Area." ECB Working Paper No. 875 (February). 
Castrén, O., T. Fitzpatrick, and M. Sydow. 2008. "Assessing Portfolio Credit Risk Changes in a Sample of EU Large and Complex Banking Groups in Reaction to Macroeconomic Shocks." Mimeo. Chan-Lau, J. A. 2006. "Fundamentals-Based Estimation of Default Probabilities: A Survey." IMF Working Paper No. 149.

Čihák, M. 2007. "Introduction to Applied Stress Testing." IMF Working Paper No. 59.

Coletti, D., R. Lalonde, M. Misina, D. Muir, P. St-Amant, and D. Tessier. 2008. "Bank of Canada Participation in the 2007 FSAP Macro Stress-Testing Exercise." Bank of Canada Financial System Review (June): 51-59.

Commission Bancaire. 2007. "The French Approach of StressTesting Credit Risk: The Methodology." Internal Document, Direction de la Surveillance Generale du Systeme Bancaire.

Deutsche Bundesbank. 2006. "Stress Test Experiences." Internal Document.

Drehmann, M. 2008. "Stress Tests: Objectives, Challenges and Modelling Choices." Economic Review (Sveriges Riksbank) 2: 60-92. Eklund, T., K. Larsen, and E. Bernhardsen. 2001. "Model for Analyzing Credit Risk in the Enterprise Sector." Economic Bulletin (Norges Bank) 3: 99-106.

Financial Stability Forum. 2008. "Report on Enhancing Market and Institutional Resilience, Follow-up on Implementation." (October).

Fiori, R., A. Foglia, and S. Iannotti. 2008. "Beyond Macroeconomic Risk: The Role of Contagion in Corporate Default Correlation." Mimeo. An earlier version of the paper was presented at the Second Expert Forum on Advanced Techniques on Stress Testing: Applications for Supervisors, International Monetary Fund and De Nederlandsche Bank, Amsterdam, October 23-24, 2007.

Hagen, J., A. Lung, K. B. Nordal, and E. Steffensen. 2005. "The IMF's Stress Testing of the Norwegian Financial Sector." Economic Bulletin (Norges Bank) 4: 202-11.

Haldane, A., S. Hall, and S. Pezzini. 2007. "A New Approach to Assessing Risks to Financial Stability." Bank of England Financial Stability Working Paper No. 2 (April).

International Monetary Fund and the World Bank. 2003. "Analytical Tools of the FSAP." 
Jiménez, G., and J. Mencía. 2007. "Modelling the Distribution of Credit Losses with Observable and Latent Factors." Banco de España Working Paper No. 0709.

Jones, M. T., P. Hilbers, and G. Slack. 2004. "Stress Testing Financial Systems: What to Do When the Governor Calls." IMF Working Paper No. 127.

Laviola, S., J. Marcucci, and M. Quagliariello. 2006. "Stress Testing Credit Risk: Experience from the Italian FSAP." Banca Nazionale del Lavoro Quarterly Review LIX (238).

Lehmann, H., and M. Manz. 2006. "The Exposure of Swiss Banks to Macroeconomic Shocks - An Empirical Investigation." Swiss National Bank Working Paper No. 4.

Marcucci, J., and M. Quagliariello. 2008. "Is Bank Portfolio Riskiness Procyclical? Evidence from Italy using a Vector Autoregression." Journal of International Financial Markets, Institutions and Money 18 (1): 46-63.

Misina, M., and D. Tessier. 2008. "Non-linearities, Model Uncertainty, and Macro Stress Testing." Bank of Canada Working Paper No. 30.

Pesaran, M. H., T. Schuermann, B.-J. Treutler, and S. M. Weiner. 2006. "Macroeconomic Dynamics and Credit Risk: A Global Perspective." Journal of Money, Credit, and Banking 38 (5): 121161.

Segoviano, M. 2006. "Conditional Probability of Default Methodology." London School of Economics Financial Market Group Discussion Paper No. 558.

Sorge, M., and K. Virolainen. 2006. "A Comparative Analysis of Macro Stress-Testing with Application to Finland." Journal of Financial Stability 2 (2): 113-51.

Sveriges Riksbank. 2006. "Using External Information to Measure Credit Risk." Financial Stability Report 1: 75-88.

Swinburne, M. 2007. "The IMF's Experience with Macro StressTesting." Presentation at the European Central Bank High Level Conference on Simulating Financial Instability, Frankfurt, July $12-13$.

van den End, J. W., M. Hoeberichts, and M. Tabbae. 2006. "Modelling Scenario Analysis and Macro Stress-Testing." De Nederlandsche Bank Working Paper No. 119.

Wilson, T. 1997. "Portfolio Credit Risk (I)." Risk 10 (9): 111-16. 